\title{
Mycobacterium tuberculosis infection induces non- apoptotic cell death of human dendritic cells
}

\author{
Ruth CM Ryan', Mary P O'Sullivan ${ }^{1 *+}$ and Joseph Keane ${ }^{1,2+}$
}

\begin{abstract}
Background: Dendritic cells (DCs) connect innate and adaptive immunity, and are necessary for an efficient CD4 ${ }^{+}$ and $\mathrm{CD}^{+} \mathrm{T}$ cell response after infection with Mycobacterium tuberculosis (Mtb). We previously described the macrophage cell death response to Mtb infection. To investigate the effect of Mtb infection on human DC viability, we infected these phagocytes with different strains of Mtb and assessed viability, as well as DNA fragmentation and caspase activity. In parallel studies, we assessed the impact of infection on DC maturation, cytokine production and bacillary survival.

Results: Infection of DCs with live Mtb (H37Ra or H37Rv) led to cell death. This cell death proceeded in a caspaseindependent manner, and without nuclear fragmentation. In fact, substrate assays demonstrated that Mtb H37Rainduced cell death progressed without the activation of the executioner caspases, 3/7. Although the death pathway was triggered after infection, the DCs successfully underwent maturation and produced a host-protective cytokine profile. Finally, dying infected DCs were permissive for Mtb H37Ra growth.

Conclusions: Human DCs undergo cell death after infection with live Mtb, in a manner that does not involve executioner caspases, and results in no mycobactericidal effect. Nonetheless, the DC maturation and cytokine profile observed suggests that the infected cells can still contribute to TB immunity.
\end{abstract}

\section{Background}

Tuberculosis is responsible for 1.7 million deaths annually, and Mycobacterium tuberculosis (Mtb) infects up to one third of the world's population $[1,2]$. Yet the human host response to Mtb infection in $90 \%$ of cases is an immune success story; where infection is followed, not by disease, but by lifelong latent infection [1].

The key role played by dendritic cells (DCs) in this successful host response has been well studied [3]. After inhalation, Mtb bacilli are phagocytosed by alveolar macrophages and DCs resident in the alveolar space. It falls to the DCs to efficiently travel to local lymph nodes and successfully present antigen to $\mathrm{T}$ cells, which generates effective cell-mediated immunity $[4,5]$. Dissemination of mycobacteria to the lymph node, which occurs in part via infected DCs, is an important precursor to $\mathrm{T}$ cell activation [6,7]. A deficiency of DCs, monocytes, B

\footnotetext{
* Correspondence: mary.osullivan@tcd.ie

+ Contributed equally

'Department of Clinical Medicine, Institute of Molecular Medicine, Trinity

College Dublin, Ireland

Full list of author information is available at the end of the article
}

and NK cells (DCML deficiency), with an as yet unknown genetic basis, has recently been defined in four subjects. Two of these subjects succumbed to mycobacterial infection: one developed disseminated BCG-osis and the other was diagnosed with spontaneous Mycobacterium kansasii infection [8]. Similarly, mutations in interferon regulatory factor 8 (IRF8), described recently in three subjects, are associated with dendritic cell deficiency resulting in susceptibility to disseminated BCG-osis [9]

We and others have shown how macrophage cell death follows infection with Mtb [10-13]. This macrophage response has consequences for aspects of innate and cell-mediated immunity $[14,15]$. The impact of Mtb infection on DC survival, however, is poorly understood. Given the non-redundant role of DCs in mycobacterial immunity [9], and their identification as a target for novel therapies and vaccines [4,16-19], we sought to define the requirements and mechanism of DC cell death after infection with Mtb. By modelling human monocyte-derived DCs in vitro, we infected DCs with 
Mtb to assess phagocyte survival, and attendant caspase activity, cytokine production and mycobactericidal effect.

Our results show that $\mathrm{Mtb}$ infection drives DC maturation and death. As we found in macrophages [10], the cell death that follows Mtb H37Ra infection is caspase-independent and is not characterised by nuclear fragmentation. In fact, infected DC death proceeds without the activation of caspases. Increased cytokine production followed DC infection with Mtb, but isolated DCs were not able to kill intracellular bacilli. Such data is of value in projecting how manipulation of DCs for new therapeutic strategies can be modelled.

\section{Results}

Live M. tuberculosis infection causes dendritic cell death Dendritic cells form an important link between the innate and the adaptive immune response, so their viability during infection may have consequences for the host. We prepared DCs from human blood as described in Methods. After 6 days' incubation, we reliably generated a population of $\mathrm{DC}-\mathrm{SIGN}^{+} \mathrm{CD} 14^{-}$cells (Figure 1A) that also had a characteristic DC appearance under microscopy, displaying dendrites after exposure to Mtb H37Ra (Figure 1B) and H37Rv (data not shown). Great care was taken to confirm a reproducible MOI for live

\section{A

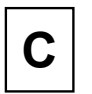

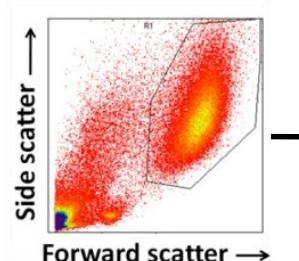
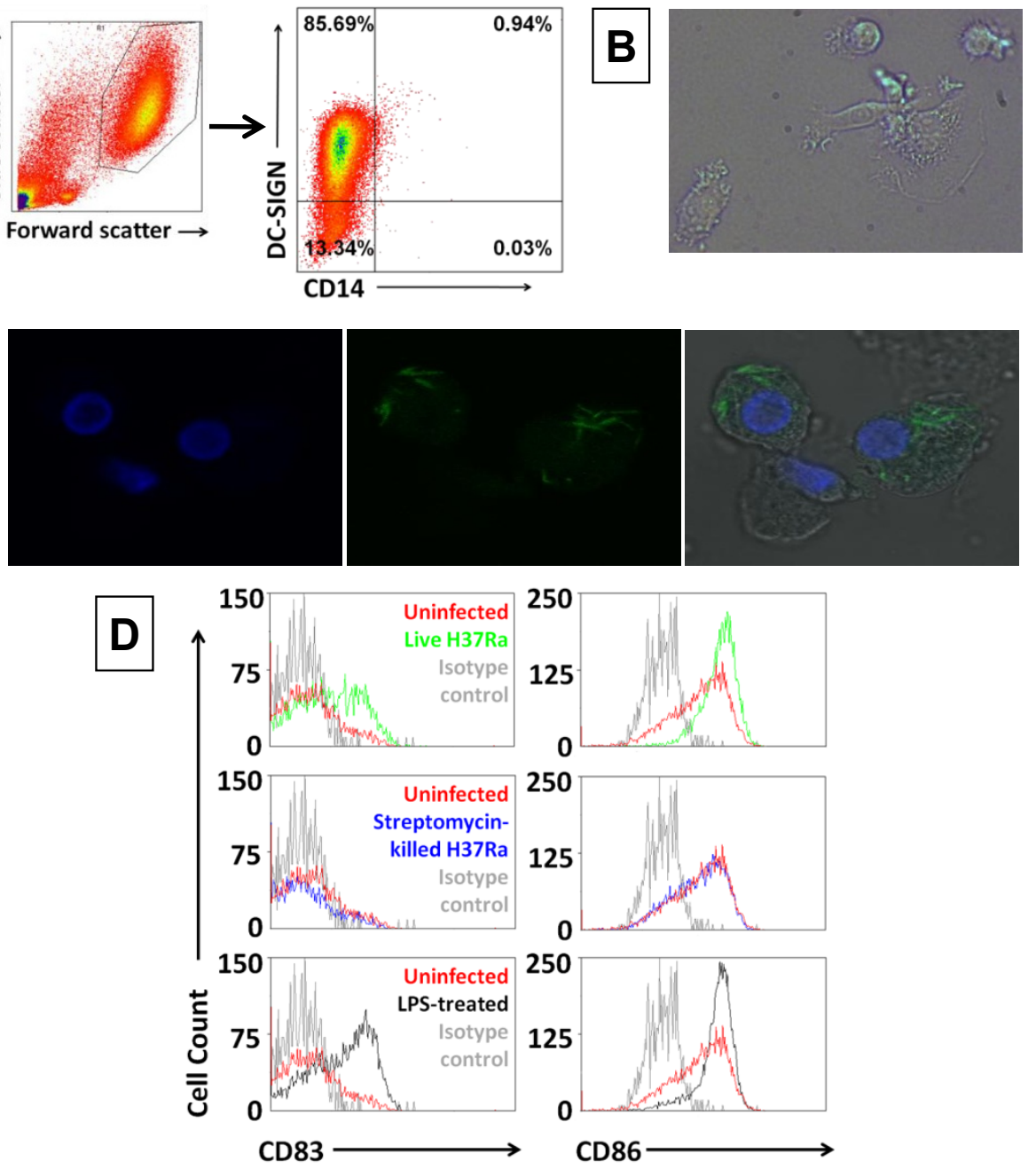

Figure 1 Dendritic cells mature after they phagocytose $\boldsymbol{M}$. tuberculosis. A. Human monocytes were separated from buffy coats by plastic adherence and cultured for 6 days in the presence of recombinant human IL-4 (40 ng/ml) and GM-CSF $(50 \mathrm{ng} / \mathrm{ml})$ to allow differentiation to DCs. Cells were analysed for CD14 and DC-SIGN expression by flow cytometry. DCs were CD14 and DC-SIGN ${ }^{+}$(typically $>85 \%$ of gated cells; both before and after infection with Mtb). Plots show uninfected, immature DCs after 6 days of cytokine treatment from 1 representative donor of 3.. B. DCs were infected with live H37Ra at MOI 1 for $24 \mathrm{~h}$ and visualised by light microscopy. C. DCs were infected with live Mtb H37Rv at $\mathrm{MOI} 10$ overnight. Bacteria were stained with auramine and nuclei with Hoechst and were visualised by confocal microscopy. Similar results were obtained with iH37Rv, live H37Ra and streptomycin-killed H37Ra (data not shown). D. DCs were infected with live Mtb H37Ra or streptomycinkilled H37Ra at MOI 1 for $48 \mathrm{~h}$. Surface expression of CD83 and CD86 was assessed by flow cytometry. The histograms show 1 representative donor of 3 . 
H37Ra and H37Rv, as well as dead Mtb bacilli, for each experiment, as discussed in Methods. Confocal microscopy (to assess phagocytosis of mycobacteria) and propidium iodide (PI) staining (to measure cell death) were carried out in DCs infected with either H37Ra or H37Rv. All other experiments were performed with H37Ra only. Figure 1C shows DCs infected with live $\mathrm{H} 37 \mathrm{Rv}$ and stained with auramine to detect mycobacteria, and demonstrates that the mycobacteria were phagocytosed by the DCs. Similar results were obtained with $\gamma$-irradiated H37Rv, live H37Ra and streptomycinkilled H37Ra (data not shown).

Maturation was assessed in DCs infected with H37Ra. In controlled experiments, DCs were infected with live or dead Mtb H37Ra or at MOI 1 for 24 h. Approximately $60 \%$ of cells had phagocytosed mycobacteria at this time point. The cells were washed to remove extracellular mycobacteria and either analysed or incubated for a further 24 or $48 \mathrm{~h}$ before analysis. DCs infected with live H37Ra displayed a mature phenotype, up-regulating CD83 and CD86 after $48 \mathrm{~h}$ infection with Mtb (Figure 1D). Streptomycin-killed H37Ra did not induce DC maturation.

To assess the relationship between intracellular infection and DC viability, we infected human monocytederived DCs with Mtb strains H37Ra and H37Rv. Viability of infected DCs (infected with 10 bacilli per cell) was assessed by PI exclusion and quantified on a GE IN Cell Analyzer 1000. Infection of DCs with either live strain was followed by cell death after 24-72 hours (Figures $2 \mathrm{~A}$ and $2 \mathrm{~B}$ ), whereas dead bacilli (streptomycinkilled or irradiated) did not elicit this response. Incubation times with each strain were optimised to provide a significant increase in the percentage of PI positive cells above background (40-60\%) while at the same time minimizing the cellular disintegration that occurs in the late stages of cell death and would lead to an underestimate of the numbers of dead cells. Longer incubation times led to the death of the majority of infected cells (> 95\%). The virulent H37Rv strain induced cell death at a faster rate than an equivalent MOI of the attenuated H37Ra strain and as a consequence, the PI exclusion assay was carried out $24 \mathrm{~h}$ after infection in H37Rv-infected DCs and $72 \mathrm{~h}$ in H37Ra-infected cells. Cell death also occurred with live H37Ra infection at the lower MOIs of 1 and 5 after $72 \mathrm{~h}$ (Figure 2C).

Having established that reduced DC viability was dependent on infection with live mycobacteria, we then investigated the mechanism of cell death in H37Rainfected DCs. We previously noted that macrophage cell death after Mtb infection results in DNA fragmentation. By ELISA, we could show that DNA fragmentation was also a feature of the DC response to viable Mtb H37Ra infection peaking at an MOI of 5 (Figure 2D).
Apoptosis results in nuclear condensation, pyknosis and, eventually, fragmentation of the nucleus into apoptotic bodies [20,21]. To determine whether this occurred during Mtb H37Ra infection, the nuclear morphology of DCs stained with Hoechst was examined by epifluorescent microscopy. The nuclei of infected cells did not undergo pyknosis or fragmentation and were similar in appearance to those of uninfected cells at 72 $\mathrm{h}$ after infection, a time at which they had undergone significant cell death. DCs treated with cycloheximide and staurosporine displayed extensive nuclear fragmentation, indicating that the cells are capable of undergoing this process when treated with apoptotic stimuli (Figure 2E).

\section{Dendritic cell death after M. tuberculosis H37Ra infection is caspase-independent and proceeds without the activation of caspase 3 and 7}

Activation of caspases is considered to be essential for classical apoptosis [22]. Therefore, we sought to establish if DC death following Mtb infection was caspase dependent. Cells were treated with the pan-caspase inhibitor Q-VD-OPh and infected with H37Ra, at an MOI of 10, and cell death was assessed using IN Cell fluorescent microscopy and analysed as before. DCs were incubated with Q-VD-OPh $4 \mathrm{~h}$ prior to infection with Mtb and the inhibitor was replenished every $24 \mathrm{~h}$ during the experiment. Cell death was assessed at $72 \mathrm{~h}$ post-infection with H37Ra. As can be seen, the inhibition of caspases by Q-VD-OPh did not interfere with the level of cell death after Mtb infection (Figure 3A), although the inhibitor did prevent the apoptosis induced by cycloheximide and staurosporine (Figure 3B) [23].

Our results so far indicated that H37Ra-infected DC death occurred with DNA fragmentation, but without nuclear karyorrhexis and was caspase-independent. Caspase-independent cell death can occur with or without caspase activation, depending on the mechanism of cell death [24]. In order to more closely examine the role of caspases in DC death induced by Mtb H37Ra infection, we analysed the activity of the executioner caspases $3 / 7$ in parallel with cell death at $24 \mathrm{~h}, 48 \mathrm{~h}$ and $72 \mathrm{~h}$ postinfection with Mtb (Figure 3C). Staurosporine (24 h treatment at all time points) and cycloheximide (24, 48 and $72 \mathrm{~h}$ treatment in parallel with infection) were used as positive controls for caspase activity, inducing increased caspase $3 / 7$ activity at all time points examined (Figure 3C). Caspase activity was measured before and after significant cell death had occurred. Cell death due to Mtb H37Ra was apparent at $72 \mathrm{~h}$ post-infection (Figure 3C) and occurred with live Mtb infection only, as in our previous experiments (Figure 2). Caspases 3/7 were not active above levels recorded in uninfected DCs at any time point examined, indicating that these 


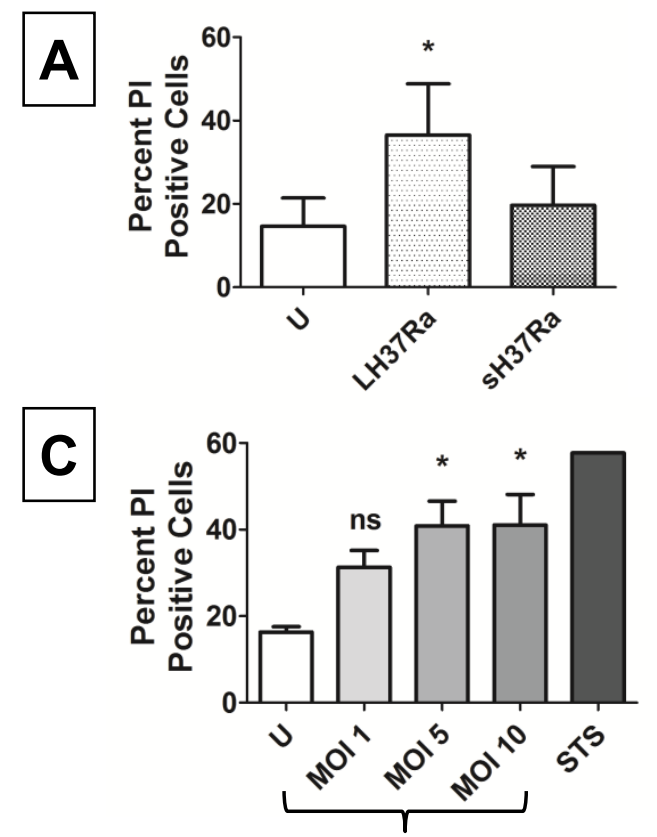

Live H37Ra
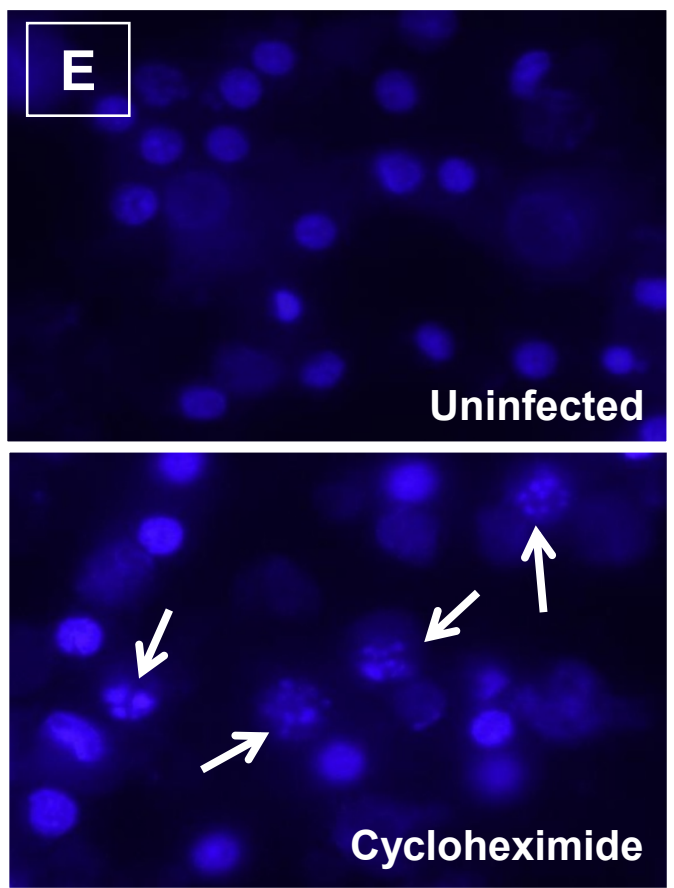

B
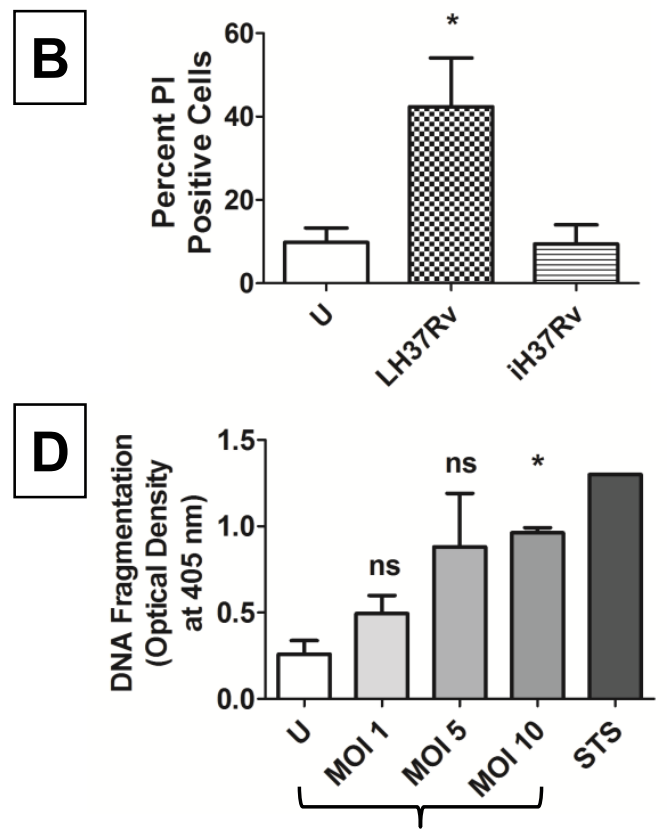

Live H37Ra
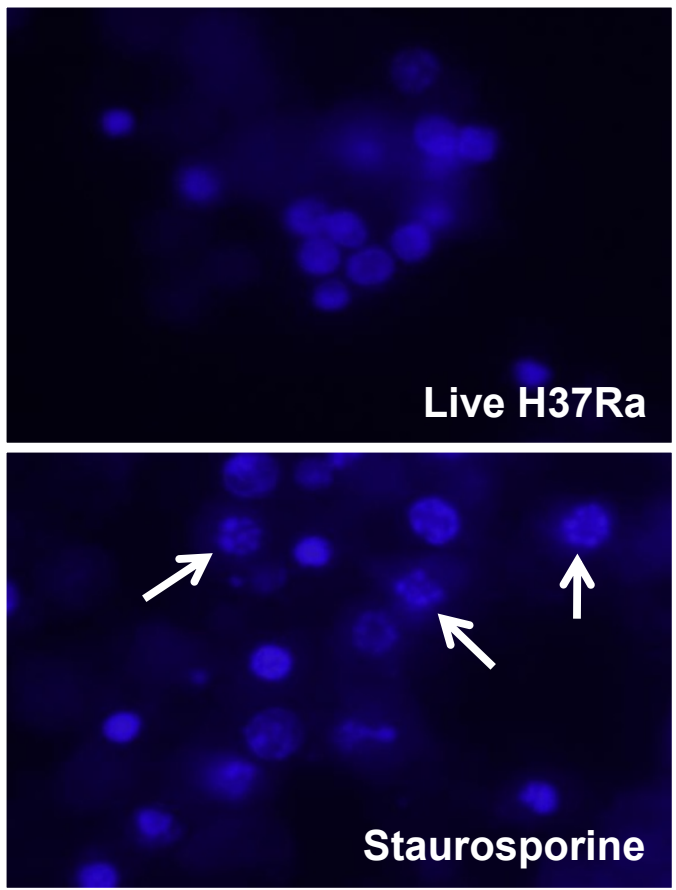

Figure 2 Live $M$. tuberculosis infection causes dendritic cell death and DNA fragmentation, without nuclear fragmentation. A - B Dendritic cells (DCs) were infected, at MOI 10 with live/dead H37Ra or live/dead H37Rv. (U = uninfected, LH37Ra = live H37Ra, sH37Ra = streptomycin-killed H37Ra, LH37Rv = live H37Rv, iH37Rv = $\gamma$-irradiated H37Rv.) Cell death was measured by propidium iodide exclusion (A) $72 \mathrm{~h}$ post-infection or (B) $24 \mathrm{~h}$ post-infection on a GE IN Cell Analyzer 1000. (A - B) are means ( \pm SEM) of 3 pooled donors. * $p<0.05$ vs. Uninfected. C. DCs were infected with live H37Ra at MOI 1, 5 or 10. Cell death was measured by propidium iodide exclusion $72 \mathrm{~h}$ after infection.

Staurosporine was used as a positive control for cell death. ${ }^{*} p<0.05$ vs. uninfected, ns - not significantly different from uninfected. D. DCs were infected with live H37Ra at MOI 1, 5 or 10. DNA fragmentation was measured by Cell Death ELISA $72 \mathrm{~h}$ after infection. ${ }^{*} p<0.05$ vs. Uninfected, ns - not significantly different from uninfected. E. DCs were infected with live H37Ra at MOI 10 for $72 \mathrm{~h}$. Nuclei were stained with Hoechst and visualised by fluorescence microscopy. Cycloheximide and staurosporine were used as positive controls for nuclear fragmentation. (C - E) are 1 representative donor of 3 , showing means ( \pm SEM) of 3 independent wells. 


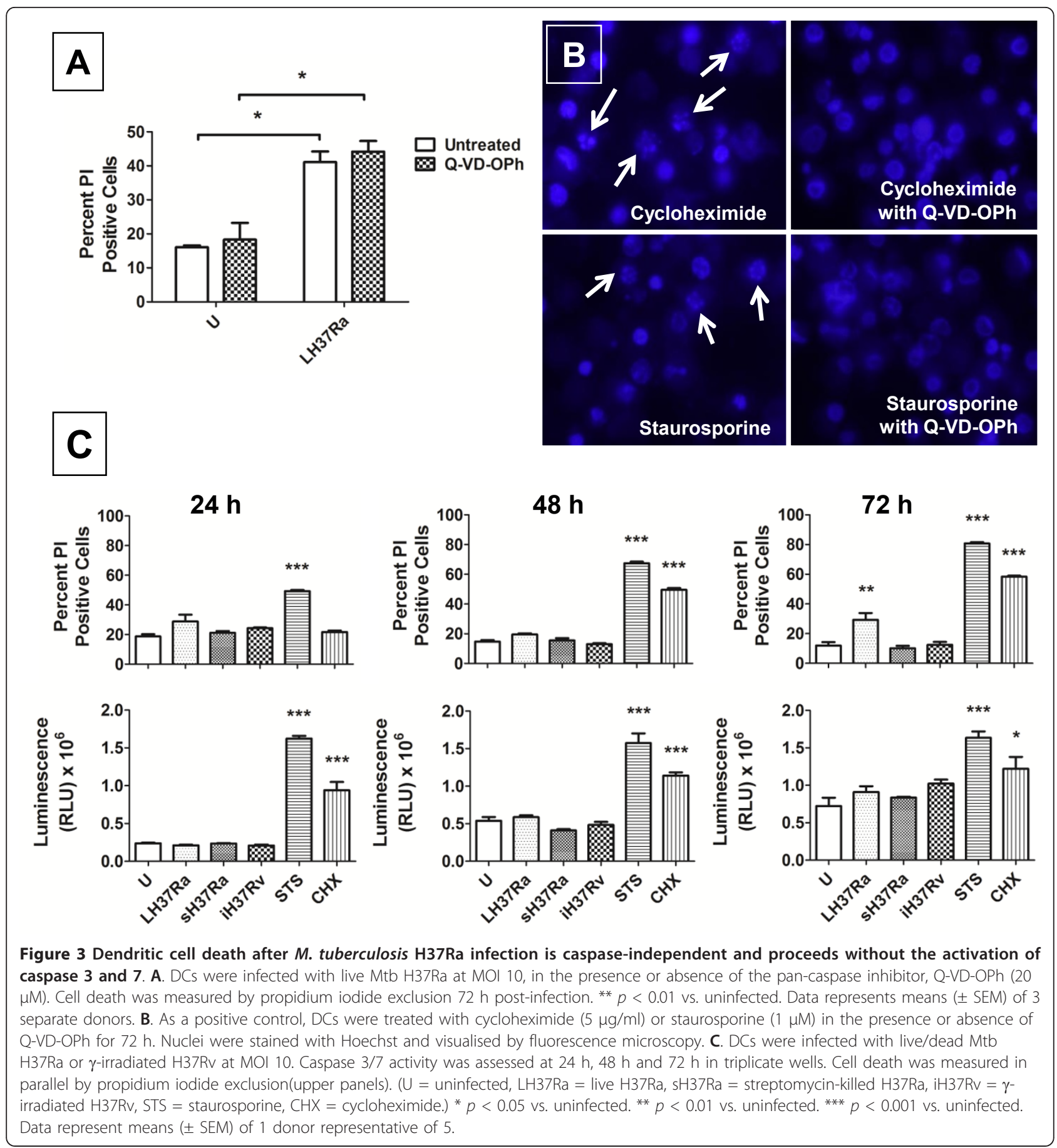

caspases are not activated during DC death after Mtb H37Ra infection.

\section{Secretion of cytokines by Mtb H37Ra-infected dendritic} cells

Although macrophages and neutrophils die after Mtb infection, these dying and dead cells have been shown to play a role in host immune responses [11,25-29]. To test if infected DCs contribute to immunity by secreting cytokines, we infected DCs with H37Ra at a low MOI of 1 bacillus per DC and assessed cytokine production (assayed by Meso Scale Discovery multiplex ELISA). Low MOI caused 40-60\% death after $72 \mathrm{~h}$ (shown in Figure $2 \mathrm{C}$ ) and was chosen to allow assessment of cytokine release at 24 and 48 hours post-infection before excessive cell death had occurred. Infection of DCs from 
each donor $(\mathrm{n}=3)$ with H37Ra consistently stimulated the release of pro- and anti-inflammatory cytokines (Figure 4) including TNF $\alpha$, IL-6, IL-8, IL-10, IL-1 $\beta$ and a modest increase in secretion of IL-12p70. There was a tendency for DCs infected with killed H37Ra to produce less IL-10, TNF $\alpha$, IL- 6 and IL- $1 \beta$ than cells infected with live H37Ra but these results did not reach statistical significance when the data was pooled due to donor variation. Other cytokines were unchanged after infection (IL-2, IFN- $\gamma$, IL-5 and IL-13; data not shown).

\section{Dendritic cells are permissive for growth of} Mycobacterium tuberculosis H37Ra

Alveolar macrophages also die after Mtb infection and yet are capable of restricting the growth of Mtb [30].
Dendritic cells are the professional cell required to activate $\mathrm{CD}^{+}$and $\mathrm{CD}^{+} \mathrm{T}$ cells to enable killing of intracellular Mtb, yet infected DCs could also limit Mtb growth. There are conflicting reports within the literature regarding the fate of Mtb strains within DCs. In the present study the ability of Mtb H37Ra to replicate within human DCs, in the presence of GM-CSF and IL4, was studied using two separate methods: colony forming unit (CFU) counts and the bioMérieux BacT/ ALERT 3D automated microbial detection system (Figure 5). At MOIs of 1, 5 and 10 bacilli per DC, we confirmed that Mtb grew over 3 days using CFU analysis on Middlebrook agar. At the same time point, we saw a similar dose-response for bacillary growth using liquid Middlebrook media in a BacT/ALERT system; a growth
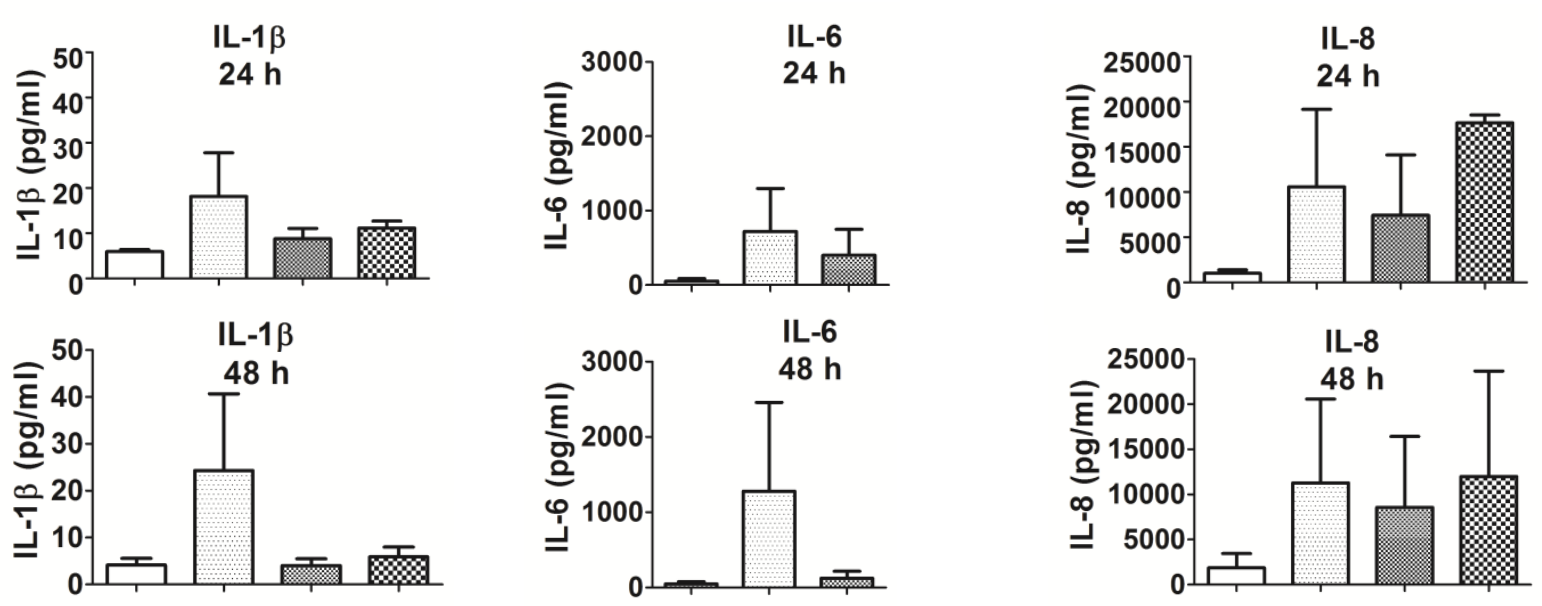

IL-12p70
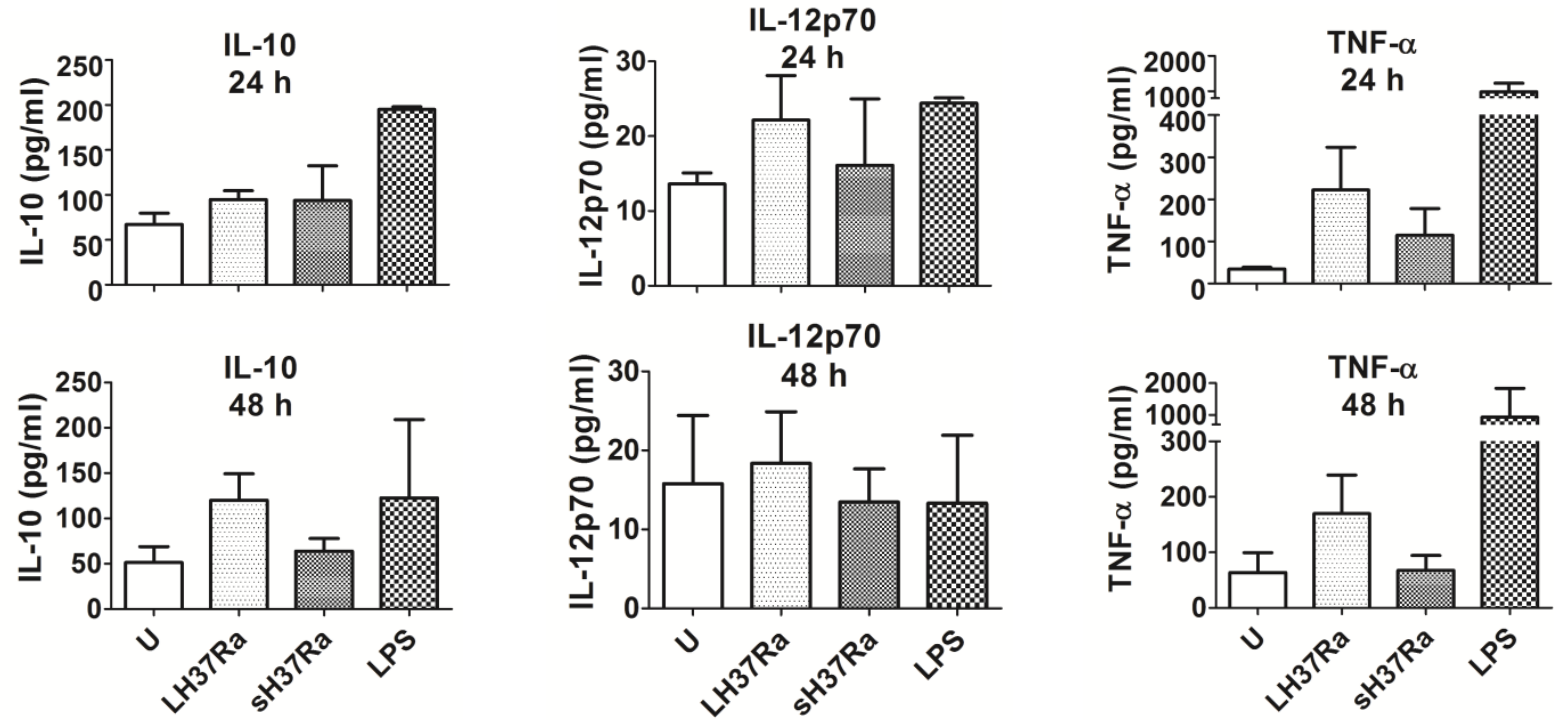

Figure 4 Dying $M$. tuberculosis-infected DCs secrete cytokines. DCs were infected with live/dead Mtb H37Ra at MOl 1 for $24 \mathrm{~h}$ or $48 \mathrm{~h}$, or treated with LPS $(1 \mu \mathrm{g} / \mathrm{ml})$ for $24 \mathrm{~h}$. ( $(\mathrm{U}=$ uninfected, LH37Ra = live H37Ra, sH37Ra = streptomycin-killed H37Ra.) Cytokine levels were measured in cell-free supernatants by ELISA. Data were analysed using the Friedman test followed by Dunn's Multiple Comparison test and represent the means ( \pm SEM) of 3 individual donors. 


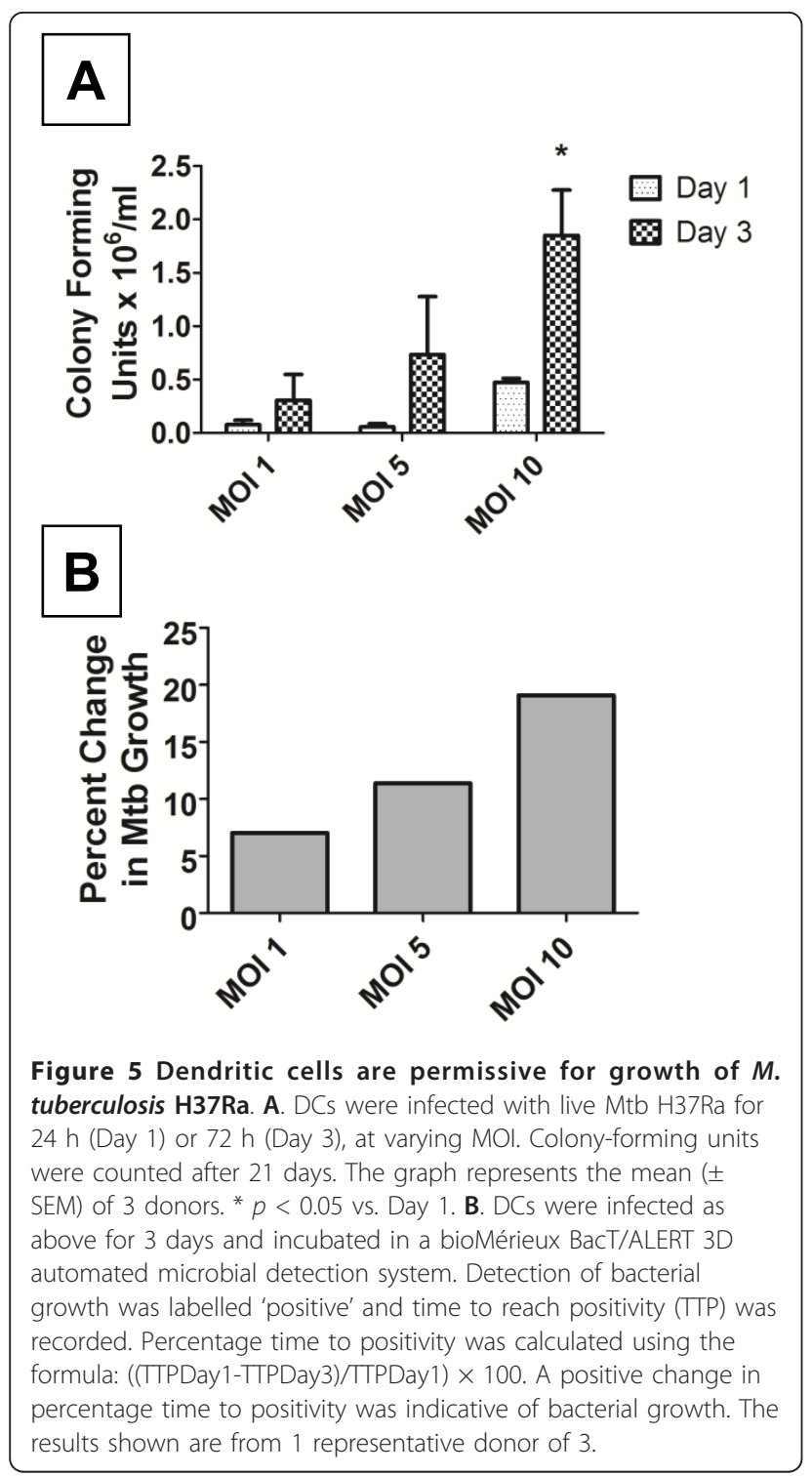

index was generated using 'time to positivity' data (see Methods). Apoptosis has been linked to improved mycobactericidal effects in macrophages $[11,31,32]$; whereas we found that Mtb replicates within DCs despite (or perhaps because of) the abundant non-apoptotic cell death that occurs during infection.

\section{Discussion}

We investigated the impact of Mtb infection on the viability of human monocyte-derived dendritic cells. We found that DC death followed infection with both the H37Ra and H37Rv strains of Mtb, required viable bacilli, and could be detected at 24 hours co-incubation. The type of cell death was atypical of apoptosis, because it lacked nuclear fragmentation. Cell death due to infection with H37Ra was caspase-independent, although it did proceed with DNA fragmentation. Caspase activation was not detected by substrate assay analysis. Although this type of cell death did not interfere with earlier DC maturation events or cytokine release, it was not associated with any detectable mycobactericidal effect of DCs.

With regard to mycobactericidal effect, DC death differs from H37Ra-infected macrophage cell death, which can kill the invading parasite [30]. In murine DCs the consequences of cell death after infection with Legionella pneumophila link caspase activity and bacterial killing [33], however we did not see caspase 3 or 7 activity, or association with Mtb killing. Other groups have examined DC mycobactericidal capacity using different models, with differing results [34-36]. Fortsch et al. and Bodnar et al. [34,35] found that DCs were permissive for growth of intracellular Mtb, while Tailleux et al. [36] reported constraint of Mtb replication within DCs without the addition of IFN- $\gamma$. The proposed difference in findings was suggested to be due to removal of the cytokines GM-CSF and IL-4 from DCs upon infection with Mtb. We maintained the GM-CSF/IL-4 supplementation of our DCs in culture to maintain the DC phenotype, and these factors did not support infected DC viability or ability to limit intracellular bacterial replication. Similar findings were reported in murine Mtb-infected DCs maintained in IL-4, which were unable to control mycobacterial growth in the absence of exogenous IFN- $\gamma$ [35]. Our experiment models the early stages of Mtb infection in the lung where newly arrived DCs may become infected before being activated by exposure to $\mathrm{T}_{\mathrm{H}} 1$ cytokines allowing uncontrolled proliferation of mycobacteria. After the initiation of a $\mathrm{T}$ cell response and the formation of the granuloma infected DCs are more likely to be exposed to IFN $\gamma$ and may be better able to control the growth of mycobacteria.

It is perhaps not surprising that DCs failed to kill bacilli by themselves, without $\mathrm{T}$ cell help. Other consequences of macrophage cell death after Mtb infection have been described, such as better antigen presentation $[14,37]$. DCs play a key role in antigen presentation, which results in activation of $T$ cell populations that can lead to efficient phagocyte killing of the intracellular bacillus, via granulysin-induced phagocyte death, or by cytokine release (e.g. IFN- $\gamma$ ) that supports the mycobactericidal capacity of phagocytes [38-41]. Although outside the scope of this current article, it is possible that dying DCs share some properties of dying macrophages, and contribute to this $\mathrm{T}$ cell response.

In the present study we found that both the attenuated H37Ra and virulent $\mathrm{H} 37 \mathrm{Rv}$ strains cause death of human DCs. The caspase-independent cell death we report in H37Ra-infected DCs appears to be neither apoptosis nor pyroptosis (both of which require caspase 
activity) $[22,42]$. There are various modes of non-apoptotic cell death, such as pyronecrosis and necroptosis, which can occur without caspase activation. The way in which cells die shapes the response of the immune system; death can be immunogenic, tolerogenic or silent $[43,44]$. Therefore, the type of cell death undergone by Mtb-infected DCs is of interest, as it may either support or inhibit cytotoxic and helper $\mathrm{T}$ cell responses. Macrophage apoptosis appears to be beneficial for the host response to tuberculosis by having direct bactericidal effects on intracellular mycobacteria and also in the stimulation of protective immunity. The genome of $M$. tuberculosis contains genes that actively inhibit macrophage apoptosis and enhance its intracellular survival, including $n u o G, p k n E$ and $\sec A 2$ [45]. It is likely that the products of these genes would also inhibit apoptosis of DCs, possibly steering the cells towards the nonapoptotic mode of cell death seen in the present study. Interestingly, foamy macrophages (which are positive for DC markers) in granulomas in the lungs of mice infected with M. tuberculosis have been found to express high levels of TNFR-associated factors (TRAFs) 1-3 which are associated with resistance to apoptosis [46]. Although H37Ra and H37Rv are highly related, being derived from the same parental H37 strain, they differ in important respects at the genetic [47], transcriptional [48] and post transcriptional [49] levels. As a result H37Ra displays several characteristics that are different from H37Rv (e.g. variations in PE/PPE/PE-PGRS proteins [47], decreased survival inside human macrophages [50,51], differences in the composition of mannose caps on lipoarabinomannin [52] and impaired ability to secrete ESAT 6 [49]) each of which could have an impact on the mode of cell death [53,54]. Indeed, similar to our previous finding in human macrophages [10], H37Rv infection killed DCs at a significantly faster rate than H37Ra. Further work will be needed to determine whether infection of DCs with H37Rv causes a similar caspase-independent mode of cell death.

Caspases can have variable effects on the immunogenic potential of dying cells. Exposure or release of damage-associated molecular pattern molecules (DAMPs), such as calreticulin, high-mobility group box 1 (HMGB1) or heat-shock proteins, by dying cells is associated with immunogenic cell death. Calreticulin exposure has been shown to be of particular importance in the induction of immunogenic cell death [55]. Exposure of calreticulin is caspase-dependent; however caspases can also mitigate the pro-inflammatory release of DAMPs from dying cells and cell death that proceeds without the activity of caspases may generate more immune-activating DAMPs $[43,56]$. Such an outcome might benefit the host response. These DAMPs could escape from the cell, unimpeded by caspase- neutralisation, and proceed to work in concert with the pro-inflammatory cytokine profile we observed, to generate a better inflammatory response in the lymph node. Yet, cross-priming of $\mathrm{T}$ cells is improved by caspasedependent macrophage apoptosis [14,57]. Whether DC death that occurs without caspase activation can elicit a $\mathrm{CD} 8^{+} \mathrm{T}$ cell response remains to be seen.

It is also possible that DC death could interfere with important DC functions such as migration to local lymph nodes for efficient antigen presentation. Others have shown that DC migration to local lymph nodes is impaired in Mtb infection [58,59], which would delay stimulation of $\mathrm{T}$ cell responses. Although DC death could contribute to this phenotype, DC migration to the draining lymph node can take 18 hours in vivo after challenge with Mtb [60]. Although we cannot extrapolate directly from our in vitro experiments to the complex environment that these cell are exposed to in vivo, infected DCs are known to traffic from the lung to lymph nodes [58]. At low MOI, the DC may arrive at the node before undergoing death in an environment where cell death can contribute to antigen cross-presentation. Elimination of the infected DCs could also deprive the host response of an important source of cytokines and antigen presentation; though data from Alaniz et al. suggest that DCs can serve, like macrophages, as a niche cell that promotes intracellular bacterial replication [61]. Mtb-infected DCs produced IL$1 \beta$, IL-6, IL-8, IL-10, IL-12p70 and TNF- $\alpha$ as reported previously [62-66] despite the fact that the majority of the cells eventually die. The cytokine profile of Mtbinfected DCs would successfully drive differentiation of $\mathrm{T}_{\mathrm{H}} 1$ and $\mathrm{T}_{\mathrm{H}} 17$ responses [67].

Mtb and the human immune system have co-evolved, so that one third of the global population has been colonised by this pathogen, yet the immune system is adequate at preventing disease $90 \%$ of the time $[1,2]$. The central cell that regulates this host response is the dendritic cell, and consequently it is increasingly viewed as a target for new therapeutic and vaccine strategies $[19,68]$. It is hoped that our description of the DC death response to Mtb infection - as pro-inflammatory, and without the activation of caspases - will inform further research that defines the $\mathrm{T}$ cell consequences of this innate response. An improved understanding of these immune processes should help advance translational research to address this global killer.

\section{Conclusions}

We have presented evidence that DCs undergo cell death after infection with Mtb in vitro, just as macrophages do. In H37Ra infection this non-apoptotic response does not limit the viability of the infecting bacillus, yet it does not interfere with DC maturation or 
cytokine production, as previously reported. The lack of caspase activity seen may also contribute to the host response by allowing DAMPS to drive anti-TB immunity, without neutralisation by these important proteases. Further work is needed to determine whether the virulent strain $\mathrm{H} 37 \mathrm{Rv}$ induces a similar non-apoptotic form of cell death in human DCs.

\section{Methods}

\section{Mycobacteria}

M. tuberculosis strains H37Ra and H37Rv were obtained from the American Type Culture Collection (Manassas, VA). Mycobacteria were propagated in Middlebrook 7H9 broth (Difco/Becton Dickinson, Sparks, MD) supplemented with albumin-dextrose-catalase supplement (Becton Dickinson) and 0.05\% Tween 80 (Difco). Aliquots were stored at $-80^{\circ} \mathrm{C}$, thawed and grown to $\log$ phase in Middlebrook 7H9 medium before use.

\section{Inactivation of mycobacteria with streptomycin}

Log-phase H37Ra were treated with streptomycin sulphate (Sigma, St. Louis, MO; $0.1 \mathrm{mg} / \mathrm{ml}$ ) for $48 \mathrm{~h}$ prior to infection. Streptomycin was thoroughly washed from mycobacteria prior to DC infection.

\section{Gamma-irradiated H37Rv}

Obtained through the NIH Biodefense and Emerging Infections Research Resources Repository, NIAID, NIH: Mycobacterium tuberculosis, Strain H37Rv, Gamma-Irradiated Whole Cells, NR-14819.

\section{Cell Culture}

Peripheral blood mononuclear cells (PBMCs) were isolated from buffy coats of anonymous healthy donors (provided, with permission, from the Irish Blood Transfusion Service). The PPD status of donors was unknown. PBMCs were separated by density centrifugation on Lymphoprep (Axis-Shield, Oslo, Norway), washed and re-suspended in serum-free RPMI 1640 (Gibco, Invitrogen, Carlsbad, CA; for plastic adherence monocyte separation) or in PBS (Sigma) with $2 \%$ defined foetal bovine serum (FBS; HyClone, Thermo Fisher Scientific, Waltham, MA) and $1 \mathrm{mM}$ EDTA (Sigma) (for immunomagnetic negative selection). Monocytes were isolated by plastic adherence, or by negative selection using the immunomagnetic negative selection EasySep Human Monocyte Enrichment Kit (STEMCELL Technologies, Vancouver, BC), as per manufacturer's instructions. For plastic adherence separation, PBMCs were incubated at $37^{\circ} \mathrm{C}$ for $2 \mathrm{~h}$ in serum-free RPMI. After incubation, unwanted cells were thoroughly washed from the adherent monocytes, which were then incubated in DC medium: RPMI supplemented with 10\% defined FBS, $40 \mathrm{ng} /$ $\mathrm{ml}$ recombinant human IL-4 and $50 \mathrm{ng} / \mathrm{ml}$ recombinant human GM-CSF (both ImmunoTools, Friesoythe, Germany). For immunomagnetic negative selection, PBMCs were incubated with magnetic particles coated with antibodies targeting unwanted cells (anti- CD2, CD3, CD16, CD19, CD20, CD56, CD66b, CD123 and glycophorin A). Labelled cells were magnetically separated and discarded, isolating the unlabelled monocytes. Monocytes were then incubated in DC medium. DCs were seeded on 24-, 48- or 96-well culture dishes at a density of $1 \times$ $10^{6}$ cells $/ \mathrm{ml}$ and cultured for 6 days prior to infection with $M$. tuberculosis. The medium, containing fresh cytokines, was replaced every 2 to 3 days. Cytokines were also replenished $24 \mathrm{~h}$ after infection with $M$. tuberculosis, to maintain cytokine activity and DC phenotype throughout Mtb infection.

\section{In vitro infection of DCs with $M$. tuberculosis}

On the day of infection, mycobacteria were centrifuged at $3,800 \mathrm{rpm}$ for $10 \mathrm{~min}$ and re-suspended in RPMI 1640 containing $10 \%$ defined FBS. Clumps were dispersed by passing the bacterial suspension through a 25 gauge needle eight times, and the sample was centrifuged at $800 \mathrm{rpm}$ for $3 \mathrm{~min}$ to remove any remaining clumps. To determine the amount of Mtb necessary to achieve the required MOI, a CrystalSpec nephelometer (BD Diagnostic Systems, Sparks, MD) was used to estimate bacterial numbers in M. tuberculosis suspension. (Nephelometer bacterial number estimates was validated by counting colony-forming units (CFU) of bacterial suspension, plated on Middlebrook 7H10 agar plates, after 14 days). MOI were then calculated as bacteria per cell. DCs were infected at various MOI for $24 \mathrm{~h}$, and extracellular bacteria were then removed by twice exchanging the medium with fresh DC medium. After $24 \mathrm{~h}$ infection, slides were prepared for acid-fast bacteria (AFB) staining to confirm phagocytosis. The cells were fixed for $10 \mathrm{~min}(\mathrm{H} 37 \mathrm{Ra})$ or $24 \mathrm{~h}(\mathrm{H} 37 \mathrm{Rv})$ in $2 \%$ paraformaldehyde (Sigma), applied to glass slides and left to air dry overnight. Slides were then stained with modified auramine O stain (Scientific Device Laboratory, Des Plaines, IL) for acid-fast bacteria. DC nuclei were counterstained with $10 \mu \mathrm{g}$ of Hoechst 33358/ml (Sigma). The number of bacilli per cell was determined by observing the slides under an inverted fluorescence microscope (Olympus IX51, Olympus Corporation, Center Valley, PA). After infection, DCs were maintained in culture at $37^{\circ} \mathrm{C}$ for 1 to 3 days before harvesting.

\section{Propidium iodide staining for IN Cell Analyzer viability assessment}

Viability was assessed using the propidium iodide (PI) exclusion method for plasma membrane integrity of cells, and the nuclei were counterstained with Hoechst. Cells were incubated with $10 \mu \mathrm{g}$ of $\mathrm{PI} / \mathrm{ml}$, Hoechst 
$33342(10 \mu \mathrm{g} / \mathrm{ml})$, and Hoechst $33358(10 \mu \mathrm{g} / \mathrm{ml})$ for 30 min at room temperature. The number of PI-positive cells relative to the total number of nuclei per field was counted by automated fluorescence microscopy using the IN Cell Analyzer 1000 and IN Cell Investigator software (GE Healthcare, Pittsburgh, PA). Each condition was assayed in triplicate, and 8 fields were counted in each well. Staurosporine (Sigma) $(1 \mu \mathrm{M}$, diluted in serum-free RPMI) was applied for $24 \mathrm{~h}$ as a positive control for cell death.

\section{DNA fragmentation (cell death ELISA)}

The cell death detection ELISA ${ }^{\text {PLUS }}$ kit (Roche Applied Science, Mannheim, Germany) was used to quantify $M$. tuberculosis-induced DNA fragmentation, as recommended by the manufacturer. Briefly, 1-3 days after infection, 48-well plates were centrifuged at $200 \times g$ to sediment detached cells, the medium was discarded, and the cells were lysed. The lysate was subjected to antigen capture enzyme-linked immunosorbent assay (ELISA) to measure free nucleosomes, and the optical density at $405 \mathrm{~nm}$ (OD405) was read on a Victor ${ }^{2}$ plate reader (Wallac/Perkin Elmer, Waltham, MA). Triplicate wells were assayed for each condition. Staurosporine (Sigma) $(1 \mu \mathrm{M}$, diluted in serum-free RPMI) was applied for 24 $h$ as a positive control for DNA fragmentation.

\section{Caspase Inhibition}

The pan-caspase inhibitor, Q-VD-OPh $(20 \mu \mathrm{M}$; Enzo Life Sciences AG, Lausen, Switzerland), was applied to DCs $4 \mathrm{~h}$ prior to infection with H37Ra and replenished every $24 \mathrm{~h}$ throughout the duration of infection

\section{Caspase-Glo Assay}

Caspase 3/7 activity was measured using the luminescent Caspase-Glo assay system (Promega, Madison, WI). DCs were cultured in 96-well plates and the assays were carried out in a total volume of $200 \mu \mathrm{l}$. After equilibration to room temperature, Caspase-Glo reagent was added to each well and gently mixed using a plate shaker at $300 \mathrm{rpm}$ for $30 \mathrm{~s}$. The plate was incubated at room temperature for 30 minutes and luminescence was then measured using a Victor $^{2}$ plate reader.

\section{Laser Scanning Confocal Microscopy}

Following infection, DCs were fixed for $10 \mathrm{~min}$ (H37Ra) or $24 \mathrm{~h}(\mathrm{H} 37 \mathrm{Rv})$ in $2 \%$ paraformaldehyde (Sigma), applied to glass slides and left to air dry overnight. The cells were then stained with modified auramine $\mathrm{O}$ stain for acid-fast bacteria and DC nuclei were counterstained with $10 \mu \mathrm{g} / \mathrm{ml}$ of Hoechst 33358. The slides were analysed using a Zeiss LSM 510 laser confocal microscope equipped with an Argon (488 $\mathrm{nm}$ excitation line; 510 $\mathrm{nm}$ emission detection) laser and a diode pulsed solid state laser (excitation $561 \mathrm{~nm}$; emission $572 \mathrm{~nm}$ long pass filter) (Carl Zeiss MicroImaging GmbH, Oberkochen, Germany). Images were generated and viewed using LSM Image Browser (Carl Zeiss MicroImaging).

\section{Flow Cytometry}

Dendritic cell surface markers were analysed by flow cytometry on a CyAn ADP flow cytometer (Dako/Beckman Coulter). Dendritic cells were infected with live H37Ra, or streptomycin-killed H37Ra at MOI 1 for 24 or $48 \mathrm{~h}$. As a positive control for maturation, uninfected DCs were treated with LPS (Sigma; $1 \mu \mathrm{g} / \mathrm{ml}$ ) for $24 \mathrm{~h}$ prior to staining for flow cytometry. Cells were incubated with antibodies for $30 \mathrm{~min}$ and fixed with $2 \%$ paraformaldehyde for at least $1 \mathrm{~h}$ prior to flow cytometry.

The following antibodies were used: FITC mouse antihuman CD14, FITC mouse IgG2a, $\kappa$ isotype control, PE mouse anti-human CD209 (DC-SIGN), PE mouse IgG2b $\kappa$ isotype control, APC mouse anti-human CD83, APC mouse IgG1 $\kappa$ isotype control, FITC mouse anti-human CD86, FITC mouse IgG1 $\kappa$ isotype control (all BD Pharmingen, San Diego, CA).

Cells were gated on forward scatter and side scatter to exclude clumps and debris. DCs were CD14 and DC$\mathrm{SIGN}^{+}$(constituting approximately $90 \%$ of gated cells). Results were analysed using Summit software version 4.3 (Dako/Beckman Coulter).

\section{Cytokine Analysis}

Dendritic cells were infected with live H37Ra or streptomycin-killed H37Ra at MOI 1 for 24 or $48 \mathrm{~h}$. LPS was applied for $24 \mathrm{~h}$ (Sigma; $1 \mu \mathrm{g} / \mathrm{ml}$ ) as a positive control for DC maturation and cytokine secretion. Cytokine secretion was measured in cell-free supernatants by ELISA using the Meso Scale Discovery SECTOR Imager 2400 and the following assays: human IL- 6 assay, and human Th1/Th2 10-cytokine multiplex assay, capable of detecting IFN- $\gamma$, IL-1 $\beta$, IL-10, IL-12p70, IL-13, IL-2, IL4 , IL-5, IL- 8 and TNF- $\alpha$ (Meso Scale Discovery, Gaithersburg, MD). IL-4 measurements were disregarded, as DCs were maintained in culture with exogenous IL-4, rendering it impossible to distinguish levels secreted by the cells themselves.

\section{Colony forming units and BacT/ALERT 3D}

Dendritic cells were harvested $24 \mathrm{~h}$ or $72 \mathrm{~h}$ after infection with $M$. tuberculosis. Cells were centrifuged and washed 3 times at $800 \mathrm{rpm}$ to remove extracellular bacteria. The cells were lysed in $0.1 \%$ Triton X-100 (Sigma) for $10 \mathrm{~min}$. The resultant bacterial suspension was then passed through a 25 gauge needle eight times to disperse clumps. The bacilli were serially diluted $\times 10^{-1}$ $\times 10^{-5}$ in Middlebrook 7H9 medium and plated on Middlebrook 7H10 agar (Difco) supplemented with oleic 
acid-albumin-dextrose-catalase (Becton Dickinson) and cycloheximide (Sigma), or inoculated into BacT/ALERT MP bottles (bioMérieux, Durham, NC). Agar plates were incubated at $37^{\circ} \mathrm{C}$ for $14-21$ days and colony forming units were counted. BacT/ALERT MP bottles were incubated in a BacT/ALERT 3D automated microbial detection system (bioMérieux) and time to reach positivity was recorded, and a growth index was calculated, using the equation ((TTPDay1-TTPDay3)/ TTPDay1)x100 as we have already published for the BD BACTEC liquid culture platform [69]. In this equation TTP Day 1 is the time to culture positivity for infected DC lysates at Day 1, and TTP Day 3 is the time to positivity for infected DC lysates at Day 3.

\section{Statistical analysis}

Results are expressed as means \pm the standard errors of the mean (SEM). The data were analyzed with GraphPad Prism 5 software (GraphPad Software, Inc., La Jolla, CA) statistical software using by repeated measures ANOVA with Tukey's post test, or (where stated) by the Friedman test followed by Dunns multiple comparison test. A $P$ value of $<0.05$ was considered statistically significant. Graphs were compiled using GraphPad Prism 5 software.

\section{Acknowledgements}

The authors wish to thank Dr Timothy Grant, Centre for Support and Analysis in Research (CSTAR) for providing advise on statistical analysis of the data. This work was supported by the Health Research Board of Ireland (HRB), Science Foundation Ireland (SFI-Immunology Cluster) and The Royal City of Dublin Hospital Trust. RCMR is a PhD candidate in the HRB-funded structured PhD programme in Molecular Medicine "From Genes to Function".

\section{Author details}

${ }^{1}$ Department of Clinical Medicine, Institute of Molecular Medicine, Trinity College Dublin, Ireland. St. James's Hospital, Dublin 8, Ireland.

\section{Authors' contributions}

RCMR performed the experiments and prepared the figures; MPOS performed the cytokine ELISAs; RCMR and MPOS analysed the data; MPOS and JK conceived of and designed the study; RCMR, MPOS and JK wrote the manuscript. All authors read and approved the final manuscript.

Received: 11 March 2011 Accepted: 24 October 2011

Published: 24 October 2011

\section{References}

1. WHO: Fact Sheet No 104: Tuberculosis. Geneva: World Health Organisation; 2007

2. WHO: Global Tuberculosis Control 2009: Epidemiology, Strategy, Financing. Geneva: World Health Organisation; 2009.

3. Schreiber HA, Sandor M: The role of dendritic cells in mycobacteriuminduced granulomas. Immunology Letters 2010, 130(1-2):26-31.

4. Tascon RE, Soares CS, Ragno S, Stavropoulos E, Hirst EMA, Colston MJ: Mycobacterium tuberculosis-activated dendritic cells induce protective immunity in mice. Immunology 2000, 99(3):473-480.

5. Tian T, Woodworth J, Sköld M, Behar SM: In vivo depletion of CD11 ${ }^{+}$cells delays the $\mathrm{CD}^{+} \mathrm{T}$ cell response to Mycobacterium tuberculosis and exacerbates the outcome of infection. The Journal of Immunology 2005, 175(5):3268-3272.
6. Chackerian AA, Alt JM, Perera TV, Dascher CC, Behar SM: Dissemination of Mycobacterium tuberculosis is influenced by host factors and precedes the initiation of T-cell immunity. Infect Immun 2002, 70(8):4501-4509.

7. Humphreys IR, Stewart GR, Turner DJ, Patel J, Karamanou D, Snelgrove RJ, Young DB: A role for dendritic cells in the dissemination of mycobacterial infection. Microbes and Infection 2006, 8(5):1339-1346.

8. Bigley V, Haniffa M, Doulatov S, Wang X-N, Dickinson R, McGovern N, Jardine L, Pagan S, Dimmick I, Chua I, Wallis J, Lordan J, Morgan C, Kumararatne DS, Doffinger $R$, van der Burg M, van Dongen J, Cant A, Dick JE, Hambleton S, Collin M: The human syndrome of dendritic cell, monocyte, B and NK lymphoid deficiency. The Journal of Experimental Medicine 2011, 208(2):227-234.

9. Hambleton S, Salem S, Bustamante J, Bigley V, Boisson-Dupuis S, Azevedo J, Fortin A, Haniffa M, Ceron-Gutierrez L, Bacon CM, et al: IRF8 mutations and human dendritic-cell immunodeficiency. New England Journal of Medicine 2011, 365:127-138

10. O'Sullivan MP, O'Leary S, Kelly DM, Keane J: A caspase-independent pathway mediates macrophage cell death in response to Mycobacterium tuberculosis infection. Infect Immun 2007, 75(4):1984-1993.

11. Rodrigues MF, Barsante MM, Alves CCS, Souza MA, Ferreira AP, AmaranteMendes GP, Teixeira HC: Apoptosis of macrophages during pulmonary Mycobacterium bovis infection: correlation with intracellular bacillary load and cytokine levels. Immunology 2009, 128(1 pt2):e691-e699.

12. Sohn H, Lee KS, Kim SY, Shin DM, Shin SJ, Jo EK, Park JK, Kim HJ: Induction of cell death in human macrophages by a highly virulent Korean isolate of Mycobacterium tuberculosis and the virulent strain H37Rv. Scandinavian Journal of Immunology 2009, 69(1):43-50

13. Keane J, Balcewicz-Sablinska MK, Remold HG, Chupp GL, Meek BB, Fenton MJ, Kornfeld H: Infection by Mycobacterium tuberculosis promotes human alveolar macrophage apoptosis. Infect Immun 1997, 65(1):298-304.

14. Schaible UE, Winau F, Sieling PA, Fischer K, Collins HL, Hagens K, Modlin RL, Brinkmann V, Kaufmann SHE: Apoptosis facilitates antigen presentation to T lymphocytes through MHC-I and CD1 in tuberculosis. Nat Med 2003, 9(8):1039-1046.

15. Winau F, Weber S, Sad S, de Diego J, Hoops SL, Breiden B, Sandhoff K, Brinkmann V, Kaufmann SHE, Schaible UE: Apoptotic vesicles crossprime CD8 T cells and protect against tuberculosis. Immunity 2006, 24(1):105-117.

16. Montes-Worboys A, Brown S, Regev D, Bellew BF, Mohammed KA, Faruqi I, Sharma P, Moudgil B, Antony VB: Targeted delivery of amikacin into granuloma. Am J Respir Crit Care Med 2010, 182(12):1546-1553.

17. McShane H, Behboudi S, Goonetilleke N, Brookes R, Hill AVS: Protective immunity against Mycobacterium tuberculosis induced by dendritic cells pulsed with both $\mathrm{CD} 8^{+}$- and $\mathrm{CD4} 4^{+}$-T-cell epitopes from antigen 85A. Infect Immun 2002, 70(3):1623-1626.

18. Badovinac VP, Messingham KAN, Jabbari A, Haring JS, Harty JT: Accelerated $\mathrm{CD}^{+} \mathrm{T}$-cell memory and prime-boost response after dendritic-cell vaccination. Nat Med 2005, 11(7):748-756.

19. Kong CU, Ng LG, Nambiar JK, Spratt JM, Weninger W, Triccas JA: Targeted induction of antigen expression within dendritic cells modulates antigen-specific immunity afforded by recombinant BCG. Vaccine 2011, 29(7):1374-1381.

20. Kerr JFR, Wyllie AH, Currie AR: Apoptosis: A basic biological phenomenon with wide-ranging implications in tissue kinetics. British Journal of Cancer 1972, 26(4):239-257.

21. Mevorach D, Trahtemberg U, Krispin A, Attalah M, Zazoun J, Tabib A, Grau A, Verbovetski-Reiner I: What do we mean when we write "senescence,"'apoptosis,"'necrosis," or "clearance of dying cells"? Annals of the New York Academy of Sciences 2010, 1209(1):1-9.

22. Kroemer G, Galluzzi L, Vandenabeele P, Abrams J, Alnemri ES, Baehrecke EH, Blagosklonny MV, El-Deiry WS, Golstein P, Green DR, Hengartner M, Knight RA, Kumar S, Lipton SA, Malorni W, Nuñez G, Peter ME, Tschopp J, Yuan J, Piacentini M, Zhivotovsky B, Melino G: Classification of cell death: recommendations of the Nomenclature Committee on Cell Death 2009. Cell Death Differentiation 2009, 16(1):3-11.

23. Caserta TM, Smith AN, Gultice AD, Reedy MA, Brown TL: Q-VD-OPh, a broad spectrum caspase inhibitor with potent antiapoptotic properties. Apoptosis 2003, 8(4):345-352.

24. Kroemer G, Martin SJ: Caspase-independent cell death. Nat Med 2005, 11(7):725-730 
25. Molloy A, Laochumroonvorapong P, Kaplan G: Apoptosis, but not necrosis, of infected monocytes is coupled with killing of intracellular bacillus Calmette-Guérin. The Journal of Experimental Medicine 1994, 180(4):1499-1509.

26. Laochumroonvorapong P, Paul S, Elkon K, Kaplan $\mathrm{G}: \mathrm{H}_{2} \mathrm{O}_{2}$ induces monocyte apoptosis and reduces viability of Mycobacterium avium- $M$. intracellulare within cultured human monocytes. Infect Immun 1996, 64(2):452-459.

27. Alemán M, de la Barrera S, Schierloh P, Yokobori N, Baldini M, Musella R, Abbate E, Sasiain M: Spontaneous or Mycobacterium tuberculosis-induced apoptotic neutrophils exert opposite effects on the dendritic cellmediated immune response. European Journal of Immunology 2007, 37(6):1524-1537.

28. Hedlund S, Persson A, Vujic A, Che KF, Stendahl O, Larsson M: Dendritic cell activation by sensing Mycobacterium tuberculosis-induced apoptotic neutrophils via DC-SIGN. Human Immunology 2010, 71(6):535-540.

29. Persson YAZ, Blomgran-Julinder R, Rahman S, Zheng L, Stendahl O: Mycobacterium tuberculosis-induced apoptotic neutrophils trigger a proinflammatory response in macrophages through release of heat shock protein 72 , acting in synergy with the bacteria. Microbes and Infection 2008, 10(3):233-240.

30. Keane J, Remold HG, Kornfeld H: Virulent Mycobacterium tuberculosis strains evade apoptosis of infected alveolar macrophages. J Immunol 2000, 164(4):2016-2020.

31. Oddo M, Renno T, Attinger A, Bakker T, MacDonald HR, Meylan PRA: Fas ligand-induced apoptosis of infected human macrophages reduces the viability of intracellular Mycobacterium tuberculosis. J Immunol 1998, 160(11):5448-5454.

32. Randhawa AK, Ziltener HJ, Stokes RW: CD43 controls the intracellular growth of Mycobacterium tuberculosis through the induction of TNF-amediated apoptosis. Cellular Microbiology 2008, 10(10):2105-2117.

33. Nogueira CV, Lindsten $T$, Jamieson AM, Case CL, Shin $\mathrm{S}$, Thompson CB, Roy CR: Rapid pathogen-induced apoptosis: a mechanism used by dendritic cells to limit intracellular replication of Legionella pneumophila. PLoS Pathog 2009, 5(6):e1000478.

34. Fortsch D, Rollinghoff M, Stenger S: IL-10 converts human dendritic cells into macrophage-like cells with increased antibacterial activity against virulent Mycobacterium tuberculosis. J Immunol 2000, 165(2):978-987.

35. Bodnar KA, Serbina NV, Flynn JL: Fate of Mycobacterium tuberculosis within murine dendritic cells. Infect Immun 2001, 69(2):800-809.

36. Tailleux L, Neyrolles O, Honore-Bouakline S, Perret E, Sanchez F, Abastado J$\mathrm{P}$, Lagrange PH, Gluckman JC, Rosenzwajg M, Herrmann J-L: Constrained intracellular survival of Mycobacterium tuberculosis in human dendritic cells. J Immunol 2003, 170(4):1939-1948.

37. Winau F, Hegasy G, Kaufmann SHE, Schaible UE: No life without deathapoptosis as prerequisite for T cell activation. Apoptosis 2005, 10(4):707-715

38. Dieli F, Troye-Blomberg M, Ivanyi J, Fournié JJ, Krensky AM, Bonneville M, Peyrat MA, Caccamo N, Sireci G, Salerno A: Granulysin-dependent killing of intracellular and extracellular Mycobacterium tuberculosis by $\mathrm{V} \gamma 9 / \mathrm{V} \delta 2$ T lymphocytes. Journal of Infectious Diseases 2001, 184(8):1082-1085.

39. Canaday DH, Wilkinson RJ, Li Q, Harding CV, Silver RF, Boom WH: $\mathrm{CD}^{+}$and $\mathrm{CD}^{+} \mathrm{T}$ cells kill intracellular Mycobacterium tuberculosis by a perforin and Fas/Fas ligand-independent mechanism. The Journal of Immunology 2001, 167(5):2734-2742.

40. Bastian M, Braun T, Bruns H, Röllinghoff M, Stenger S: Mycobacterial lipopeptides elicit CD4 ${ }^{+}$CTLs in Mycobacterium tuberculosis-infected humans. The Journal of Immunology 2008, 180(5):3436-3446.

41. Martino A, Casetti R, Sacchi A, Poccia F: Central memory Vy9V $\delta 2$ T lymphocytes primed and expanded by Bacillus Calmette-Guérin-infected dendritic cells kill mycobacterial-infected monocytes. The Journal of Immunology 2007, 179(5):3057-3064.

42. Fernandes-Alnemri T, Wu J, Yu JW, Datta P, Miller B, Jankowski W, Rosenberg S, Zhang J, Alnemri ES: The pyroptosome: a supramolecular assembly of ASC dimers mediating inflammatory cell death via caspase1 activation. Cell Death Differ 2007, 14(9):1590-1604.

43. Green DR, Ferguson T, Zitvogel L, Kroemer G: Immunogenic and tolerogenic cell death. Nat Rev Immunol 2009, 9(5):353-363.

44. Torchinsky MB, Garaude J, Blander JM: Infection and apoptosis as a combined inflammatory trigger. Current Opinion in Immunology 2010, 22(1):55-62.
45. Briken $V$, Miller JL: Living on the edge: inhibition of host cell apoptosis by Mycobacterium tuberculosis. Future Microbiology 2008, 3(4):415-422.

46. Ordway D, Henao-Tamayo M, Orme IM, Gonzalez-Juarrero M: Foamy macrophages within lung granulomas of mice infected with Mycobacterium tuberculosis express molecules characteristic of dendritic cells and antiapoptotic markers of the TNF receptor-associated factor family. The Journal of Immunology 2005, 175(6):3873-3881.

47. Zheng H, Lu L, Wang B, Pu S, Zhang X, Zhu G, Shi W, Zhang L, Wang H, Wang S, Zhao G, Zhang Y: Genetic basis of virulence attenuation revealed by comparative genomic analysis of Mycobacterium tuberculosis strain H37Ra versus H37Rv. PLoS One 2008, 3(6):e2375.

48. Li AH, Waddell SJ, Hinds J, Malloff CA, Bains M, Hancock RE, Lam WL, Butcher PD, Stokes RW: Contrasting transcriptional responses of a virulent and an attenuated strain of Mycobacterium tuberculosis infecting macrophages. PLoS One 2010, 5(6):e11066.

49. Frigui W, Bottai D, Majlessi L, Monot M, Josselin E, Brodin P, Garnier T, Gicquel B, Martin C, Leclerc C, Cole ST, Brosch R: Control of M. tuberculosis ESAT-6 secretion and specific T cell recognition by PhoP. PLoS Pathog 2008, 4(2):e33.

50. Silver RF, Li Q, Ellner JJ: Expression of virulence of Mycobacterium tuberculosis within human monocytes: virulence correlates with intracellular growth and induction of tumor necrosis factor alpha but not with evasion of lymphocyte-dependent monocyte effector functions. Infect Immun 1998, 66(3):1190-1199.

51. Zhang M, Gong J, Lin Y, Barnes PF: Growth of virulent and avirulent Mycobacterium tuberculosis strains in human macrophages. Infect Immun 1998, 66(2):794-799.

52. Nigou J, Vercellone A, Puzo G: New structural insights into the molecular deciphering of mycobacterial lipoglycan binding to C-type lectins: lipoarabinomannan glycoform characterization and quantification by capillary electrophoresis at the subnanomole level. J Mol Biol 2000, 299(5):1353-1362.

53. Barry DP, Beaman BL: Modulation of eukaryotic cell apoptosis by members of the bacterial order Actinomycetales. Apoptosis 2006, 11(10):1695-1707.

54. Welin A, Eklund D, Stendahl O, Lerm M: Human macrophages infected with a high burden of ESAT-6-expressing $M$. tuberculosis undergo caspase-1- and cathepsin B-independent necrosis. PLoS One 2011, 6(5): e20302.

55. Obeid M, Tesniere A, Ghiringhelli F, Fimia GM, Apetoh $L$, Perfettini $J$, Castedo M, Mignot G, Panaretakis T, Casares N, Métivier D, Larochette N, van Endert P, Ciccosanti F, Piacentini M, Zitvogel L, Kroemer G: Calreticulin exposure dictates the immunogenicity of cancer cell death. Nat Med 2007, 13(1):54-61.

56. Kazama H, Ricci J-E, Herndon JM, Hoppe G, Green DR, Ferguson TA: Induction of immunological tolerance by apoptotic cells requires caspase-dependent oxidation of high-mobility group box-1 protein Immunity 2008, 29(1):21-32.

57. Pang B, Neijssen J, Qiao X, Janssen L, Janssen H, Lippuner C, Neefjes J: Direct antigen presentation and gap junction mediated crosspresentation during apoptosis. The Journal of Immunology 2009, 183(2):1083-1090.

58. Wolf AJ, Linas B, Trevejo-Nunez GJ, Kincaid E, Tamura T, Takatsu K, Ernst JD: Mycobacterium tuberculosis infects dendritic cells with high frequency and impairs their function in vivo. J Immunol 2007, 179(4):2509-2519.

59. Wolf AJ, Desvignes L, Linas B, Banaiee N, Tamura T, Takatsu K, Ernst JD: Initiation of the adaptive immune response to Mycobacterium tuberculosis depends on antigen production in the local lymph node, not the lungs. J Exp Med 2008, 205(1):105-115.

60. Khader SA, Partida-Sanchez S, Bell G, Jelley-Gibbs DM, Swain S, Pearl JE, Ghilardi N, deSauvage FJ, Lund FE, Cooper AM: Interleukin 12p40 is required for dendritic cell migration and $\mathrm{T}$ cell priming after Mycobacterium tuberculosis infection. J Exp Med 2006, 203(7):1805-1815.

61. Alaniz RC, Sandall S, Thomas EK, Wilson CB: Increased dendritic cell numbers impair protective immunity to intracellular bacteria despite augmenting antigen-specific $\mathrm{CD}^{+} \mathrm{T}$ lymphocyte responses. J Immunol 2004, 172(6):3725-3735.

62. Remoli ME, Giacomini E, Petruccioli E, Gafa V, Severa M, Gagliardi MC, lona E, Pine R, Nisini R, Coccia EM: Bystander inhibition of dendritic cell differentiation by Mycobacterium tuberculosis-induced IL-10. Immunol Cell Biol 2010. 
63. Floto RA, MacAry PA, Boname JM, Mien TS, Kampmann B, Hair JR, Huey OS, Houben ENG, Pieters J, Day C, Oehlmann W, Singh M, Smith KG, Lehner PJ: Dendritic cell stimulation by mycobacterial Hsp70 is mediated through CCR5. Science 2006, 314(5798):454-458.

64. Rajashree P, Supriya P, Das SD: Differential migration of human monocyte-derived dendritic cells after infection with prevalent clinical strains of Mycobacterium tuberculosis. Immunobiology 2008, 213(7):567-575.

65. Bansal K, Sinha AY, Ghorpade DS, Togarsimalemath SK, Patil SA, Kaveri SV, Balaji KN, Bayry J: Src homology 3-interacting domain of Rv1917c of Mycobacterium tuberculosis induces selective maturation of human dendritic cells by regulating PI3K-MAPK-NF-KB signaling and drives Th2 immune responses. Journal of Biological Chemistry 2010, 285(47):36511-36522.

66. Wang C, Peyron P, Mestre O, Kaplan G, van Soolingen D, Gao Q, Gicquel B, Neyrolles O: Innate immune response to Mycobacterium tuberculosis Beijing and other genotypes. PLOS ONE 2010, 5(10):e13594.

67. Torchinsky MB, Garaude J, Martin AP, Blander JM: Innate immune recognition of infected apoptotic cells directs $T_{H} 17$ cell differentiation. Nature 2009, 458(7234):78-82.

68. Nakano H, Nagata T, Suda T, Tanaka T, Aoshi T, Uchijima M, Kuwayama S, Kanamaru N, Chida K, Nakamura H, Okada M, Koide Y: Immunization with dendritic cells retrovirally transduced with mycobacterial antigen $85 \mathrm{~A}$ gene elicits the specific cellular immunity including cytotoxic Tlymphocyte activity specific to an epitope on antigen 85A. Vaccine 2006, 24(12):2110-2119.

69. Keane J, Shurtleff B, Kornfeld H: TNF-dependent BALB/C murine macrophage apoptosis following Mycobacterium tuberculosis infection inhibits bacillary growth in an IFN- $\gamma$ independent manner. Tuberculosis 2002, 82(2-3):55-61.

doi:10.1186/1471-2180-11-237

Cite this article as: Ryan et al:: Mycobacterium tuberculosis infection induces non-apoptotic cell death of human dendritic cells. BMC Microbiology 2011 11:237.

\section{Submit your next manuscript to BioMed Central and take full advantage of:}

- Convenient online submission

- Thorough peer review

- No space constraints or color figure charges

- Immediate publication on acceptance

- Inclusion in PubMed, CAS, Scopus and Google Scholar

- Research which is freely available for redistribution

Submit your manuscript at www.biomedcentral.com/submit 